\title{
Optimization of Magnetic Flux-path Design for Reduction of Shaft Voltage in IPM-Type BLDC Motor
}

\author{
Kyung-Tae Kim* and Jin Hur ${ }^{\dagger}$
}

\begin{abstract}
In this paper, we propose a method for suppressing shaft voltage by modifying the rotor shape and the permanent magnets in interior permanent magnet type high voltage motors. The shaft voltage, which adversely affects the bearing by occurring bearing current, is induced by parasitic components and the leakage flux in motor-driven systems as well as inherent linkage flux between main magnetic flux and shaft according to rotor configuration. Thus, shaft voltage should be analyzed and considered under inverter-driven and non-inverter-driven conditions because inherent linkage flux can analyze under non-inverter-driven condition. In this study, we designed re-arrangement magnet and re-structuring rotor to minimize the shaft voltage. In addition, we optimized the proposed models. The shaft voltage suppression effect of the designed model was validated experimentally and by comparative finite element analysis.
\end{abstract}

Keywords: High voltage motor, IPM-type BLDC motor, Shaft voltage

\section{Introduction}

The usage of the interior permanent magnet (IPM)-type brushless DC motors (BLDCMs) is increasing in industrial applications and electrical machines because of its high power density and efficiency [1]. In these systems, shaft voltage has become a serious problem owing to occurrence of bearing current, which reduces the lifetime and reliability of the motor. If shaft voltage is constantly maintained for a long time, it eventually leads to breakdown of the motor.

There are four generation causes of shaft voltage in a motor: electrostatic shaft voltage, magnetic unbalanced shaft voltage, electromagnetic shaft voltage and shaft voltage from the external power supply. Among these four generation causes, shaft voltage for electromagnetic reason and external power-supply is the primary causes of shaft voltage. In case of the electromagnetic reason, magnetic unbalanced is primary reason for shaft voltage generation. It is usually caused by modification of the stator core and eccentricity between the stator and rotor. On the other hand, shaft voltage by the external power supply is caused by the common mode voltage, which is due to a parasitic component and leakage flux from the high input voltage and high frequency of the inverter $[2,3]$.

In addition, when the rotor is rotating under noninverter-driven condition, linkage flux is induced at the shaft by main magnetic flux of PM. For this reason, shaft voltage is induced by the linkage flux between main magnetic flux and shaft. We named it inherent shaft voltage because it depends on the rotor configuration. In particular,

$\dagger$ Corresponding Author: Dept. of Electrical Engineering, Ulsan University, Korea. (jinhur@ulsan.ac.kr)

* Dept. of Electrical Engineering, Ulsan University, Korea. (kkt2782 (anate.com)

Received: April 24, 2014; Accepted: July 9, 2014 high voltage IPM-type BLDCM using neodymium PM should be considered the effect on inherent shaft voltage to prevent the reduction of their lifetime.

In the previous, many studies on insulated bearings, shaft grounding rings, grounding brushes, Faraday shields, conductive grease, insulated rotors and etc. have been conducted to suppress the shaft voltage [2,3]. Although there are many ways to suppress the shaft voltage, they cannot be used in special circumstances. For example, a motor using the fragile insulating material cannot withstand in high-temperature and in the deep sea conditions because of high hydraulic pressure. Thus, the study for robust design method against high-temperature and hydraulic pressure should be conducted.

In this study, we proposed method for suppressing shaft voltage, which is robust in high-temperature and hydraulic pressure conditions through the design of flux-path. In order to change the flux-path, we modified the magnet-type from parallel magnet-type to V-shape magnet-type. In addition, we inserted barriers surrounding shaft to reduce the flux flow through the shaft. Based on this method, we optimized IPM-type high-voltage BLDCM within a range to maintain output torque of initial motor. Consequently, we validated shaft voltage suppression in IPM-type highvoltage motors through simulation and experiment.

\section{Occurrences of Inherent Shaft Voltage}

Fig. 1 shows the flux lines for parallel-shape and Vshape IPM-type BLDCMs under non-inverter-driven condition. The flux lines of both motors are flow through the shaft. For these flux components, linkage flux between the main magnetic flux and shaft is generated, and 

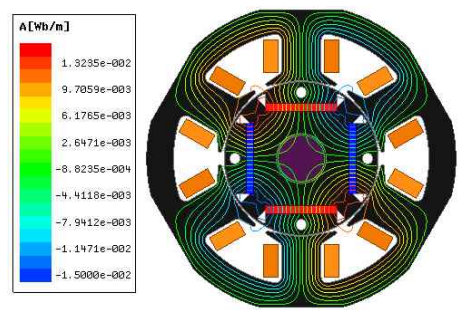

(a) Parallel-shape

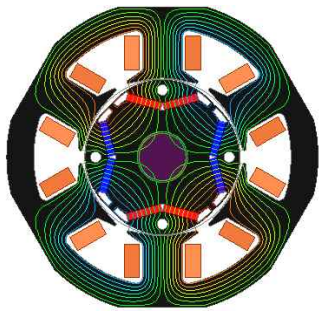

(b) V-shape
Fig. 1. Flux lines for IPM-type BLDCMs

therefore shaft voltage is induced. We named it inherent shaft voltage.

Inherent shaft voltage depends on the rotor configuration because influence of inherent shaft voltage is decided according to geometry and arrangement of the rotor and $\mathrm{PM}$, respectively. In addition, inherent shaft voltage affects and reflects on the extrinsic shaft voltage under inverterdriven condition. Therefore, design for preventing the inherent shaft voltage should be taken into account in order to improve the lifetime and durability of the PM motors.

\section{Occurrences of Extrinsic Shaft Voltage}

\subsection{Electrostatic shaft voltage}

Static electricity by the friction in the motor-driven systems includes electrostatic capacity. Thus, it leads to occurrence of an electrostatic shaft voltage. In addition, the electrostatic shaft voltage in motor driven-system work as a direct current component, and it mostly occurs in the drive belts connected between the motor and loads.

\subsection{Magnetic unbalanced shaft voltage}

Magnetic unbalanced shaft voltage is induced by structure, material, and deviation of the motors. For example, the commissure of the segmented stator core, the segmentcontact of the core, transformation of the stator core and the eccentricity between the rotor and stator are cause of the magnetic unbalanced shaft voltage. Thus, the linkage magnetic flux of the shaft occurred by magnetic unbalances.

\subsection{Shaft voltage from the external power supply}

High frequency and leakage current from external power supply generates the common mode voltage. It not only occurs between the inverter and motor but also lead to generation of the shaft voltage. Therefore, the common mode voltage by external power supply has become a serious problem.

\subsection{Electromagnetic shaft voltage}

Electromagnetic shaft voltage under inverter-driven condition occurs by the magnetic field that rotates with the shaft, the stationary magnetic field in the casing, combination with the magnetic field of the rotor and stator, and the residual magnetism of components. The magneticinduced voltage causes vibration and instability of the rotated axis.

\section{Calculation of the Inherent and Extrinsic Shaft Voltage}

\subsection{Calculation of the inherent shaft voltage}

Inherent shaft voltage can be calculated by the Faraday's law as (1) because it is induced by linkage flux between the main magnetic flux and shaft.

$$
e_{\text {shaft }}=\frac{d \lambda_{\text {shaft }}}{d t}
$$

where $e_{\text {shaft }}$ is the inherent shaft voltage, and $\lambda_{\text {shaft }}$ is the linkage flux between the main magnetic flux and the shaft.

The linkage flux between the shaft and main magnetic flux can be expressed as

$$
\lambda_{\text {shaft }}=N \varphi_{\text {shaft }}=N B_{\text {shaft }} A_{\text {shaft }}
$$

where $N$ is the number of windings, $\varphi_{\text {shaft }}$ is the magnetic flux at the shaft, $B_{\text {shaft }}$ is the magnetic flux density at the shaft, and $A_{\text {shaft }}$ is the cross-sectional area of the shaft.

Therefore, the inherent shaft voltage can be rewritten as

$$
e_{\text {shaft }}=N A_{\text {shaft }} \frac{d B_{\text {shaft }}}{d t}
$$

Here, $N$ is indicated the shaft and assumed parallel single coil because the shaft has only on path and is not winded.

\subsection{Calculation of the extrinsic shaft voltage}

When the motor is operating, the parasitic component and leakage flux occur chiefly because of the high input voltage and the high frequency of the inverter. In order to calculate extrinsic shaft voltage, first, the parasitic component should be calculated. A detailed mathematical analysis will be carried out to determine the effects on these parameters of the motor shaft voltage. Fig. 2 (a) shows the structure of a high-voltage motor. Fig. 2 (b) shows the equivalent circuit including the common mode voltage for calculating shaft voltage [4-7].

\subsubsection{Composite capacitance between the winding and the stator core $\left(C_{s}\right)$}

There are 4 surfaces which surround the winding in the 


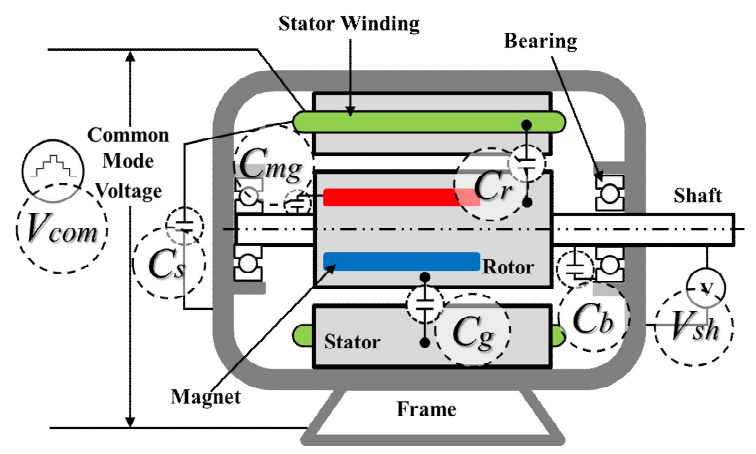

(a) Structure of IPM-type motor

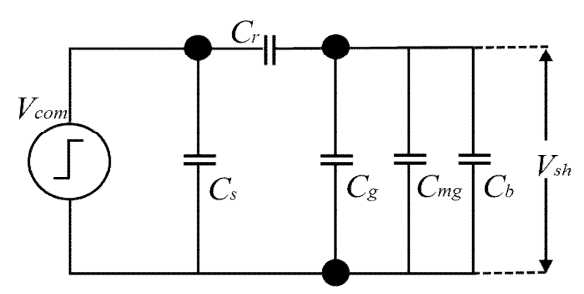

(b) Equivalent circuit

Fig. 2. Schematics of an IPM-type high voltage motor.
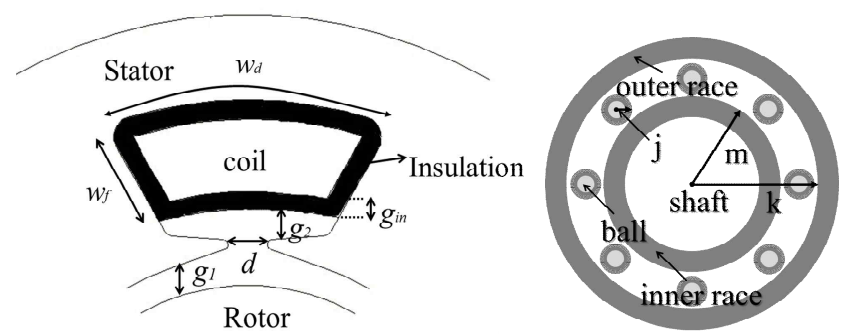

(a) Slot design factors.

(b) Ball bearing factors.

Fig. 3. Parameters of an IPM-type motor.

slot. The Cs can be calculated as

$$
C_{s}=\frac{N_{s} \varepsilon_{0} \varepsilon_{r c}\left(w_{d}+2 \times w_{f}\right) \times L_{s}}{g_{\text {in }}}
$$

where, $N_{s}$ is the number of slots, $w_{d}$ is the slot width, $w_{f}$ is the slot height, $L_{s}$ is the stator length, $g_{\text {in }}$ is the insulation thickness and $\varepsilon_{r c}$ is the dielectric constant of the coil.

\subsubsection{Composite capacitance between the winding and the $\operatorname{rotor}\left(C_{r}\right)$}

By considering the air-gap to be much smaller than the outer diameter of the rotor, a capacitance coupling between rotor and stator frame in stator slot can be calculated as (5), and slot design factors are shown in Fig. 3 (a).

$$
C_{r}=\frac{\varepsilon_{0} \times(d-t)}{t+g_{1}+g_{2}}
$$

\subsubsection{Electrostatic capacity between the stator core and the rotor core $\left(C_{g}\right)$}

Electrostatic capacitance of the stator and the rotor surface were measured. $C_{g}$ can be calculated as follows

$$
C_{g}=\left(\varepsilon_{0} \times \pi \times L_{r}\right) / \ln \left(\frac{b}{a}\right)
$$

where, $L_{r}$ is the rotor length, $a$ is the radius of the rotor, and $b$ is the radius of the inside stator.

\subsubsection{Magnet capacitance $\left(C_{m g}\right)$}

The magnet capacitance between the rotor surface and the shaft $\left(C_{m g}\right)$ can be calculated as

$$
C_{m g}=\frac{N_{m} \times \varepsilon_{0} \times w_{m} \times L_{r}}{d_{m}}
$$

where, $N_{m}$ is the number of magnets, $w_{m}$ is the magnet width and $d_{m}$ is the distance between the magnet and the shaft.

\subsubsection{Ball bearing capacitance $\left(C_{B}\right)$}

The ball bearing capacitance is calculated as (8), and ball bearing factors are shown in Fig. 3 (b).

$$
C_{B}=2 \pi \varepsilon_{0} \varepsilon_{r b} L_{b} / \ln \left(\frac{k-m}{2 j}\right)
$$

where, $L_{b}$ is the roller length of the bearing, $k$ is the inner radius of the bearing outer race, $m$ is the outer radius of the bearing inner race, $j$ is the ball radius of the bearing and $\varepsilon_{r b}$ is the dielectric constant of the coil.

\subsubsection{Extrinsic shaft voltage by common mode voltage}

Eq. (9) shows the shaft voltage of the motor. Eq. (10) is another form of Eq. (9). Eq. (11) shows common mode voltage, which is obtained by adding the three voltages from the three inverter legs.

$$
\begin{gathered}
\frac{1}{C_{r}} \frac{d\left(V_{s h}-V_{c o m}\right)}{d t}+\left(\frac{1}{C_{b}}+\frac{1}{C_{g}}+\frac{1}{C_{m g}}\right) \frac{d\left(V_{s h}\right)}{d t}=0 \\
V_{s h}=\frac{C_{r}}{C_{r}+C_{b}+C_{g}+C_{m g}} \times V_{c o m} \\
V_{c o m}=\frac{V_{a o}+V_{b o}+V_{c o}}{3}
\end{gathered}
$$

\section{Design of Proposed Model}

Numerous papers have been published by both motor 
manufacturers and drive manufacturers in the last several years that attempt to understand the causes of shaft voltage in motors and to find a solution to eliminate electrical bearing damage. The bearing can be protected from shaft voltage in the following ways: insulated bearings, shaft grounding rings, grounding brushes, Faraday shield, conductive grease, and insulated rotors. There are many methods of suppressing shaft voltage, but some of these cannot be used in special circumstances. For example, fragile insulating materials cannot be used at extreme temperature because they are easily broken or melted. In addition, the vessel cannot be earthed. In such cases, there is no option to suppress shaft voltage by modifying the magnetic and electric circuits [2-4].

Therefore, we re-designed magnetic circuit of the motor and used an optimization technique to suppress shaft voltage. Fig. 4 shows the design variable applied in the optimization. From (4)-(11), these design variables mainly affect shaft voltage as shown (12) and (13). Figs. 5, 6, and 7 show the design results for the position and thickness of the magnetic flux barrier and the arc radius, respectively.

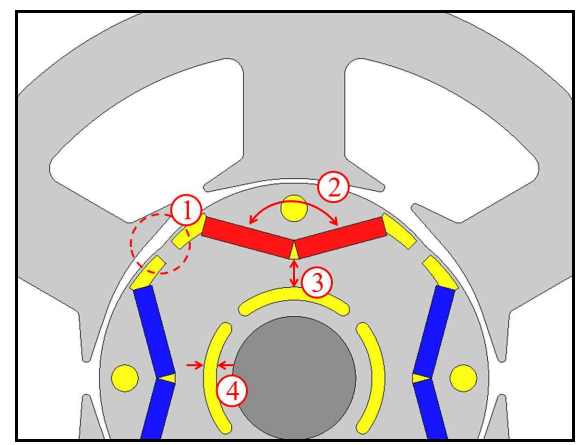

(1) Arc radius $\left(g_{a r c}\right)$, (2) Sloped PM angle $\left(\theta_{P M}\right)$,

(3) Distance between magnet and shaft $\left(d_{m}\right)$, (4) Flux barrier thickness $\left(d_{t h}\right)$

Fig. 4. Structure of the design variables

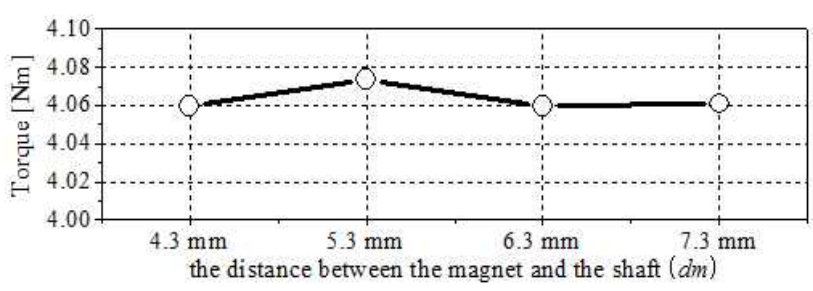

(a) The average torque.

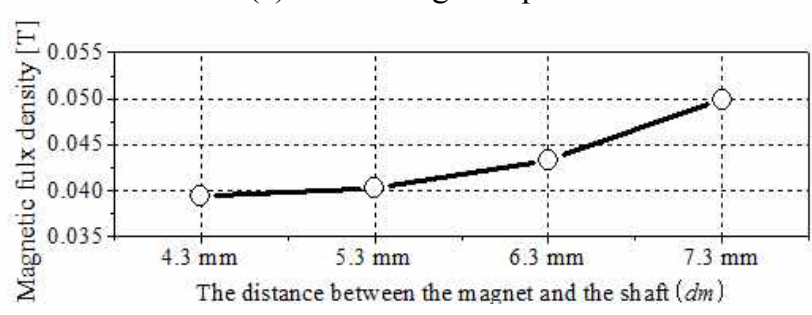

(b) The magnetic flux density on the shaft.

Fig. 5. The optimization results for flux barrier position
The average torque of the applied model has almost the same value. As shown in Fig. 5, for $4.3 \mathrm{~mm}$, we get the lowest value of the magnetic flux density on the shaft. However, when the motor rotates in the case of $4.3 \mathrm{~mm}$, the rotor core can get ruptured because the thickness between the barrier and the shaft is thin. Therefore, $5.3 \mathrm{~mm}$ is the optimal result. As shown in Fig. 6, for $1 \mathrm{~mm}$, we get the lowest value of the magnetic flux density on the shaft. For $26 \mathrm{~mm}$, we can get the lowest value of the magnetic flux density on the shaft as shown in Fig. 7. In addition, the arc shape is modified to reduce the cogging torque. Table I shows the final optimized results for the proposed motor.

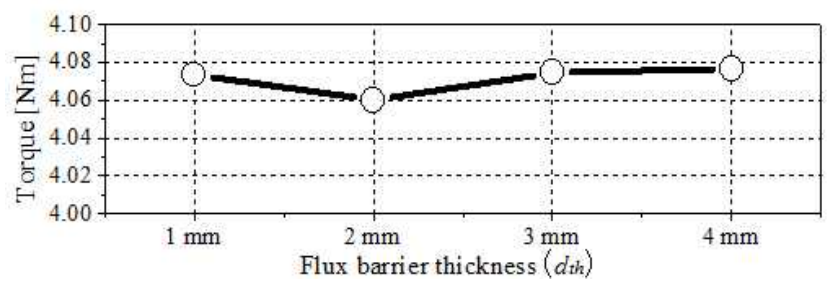

(a) The average torque.

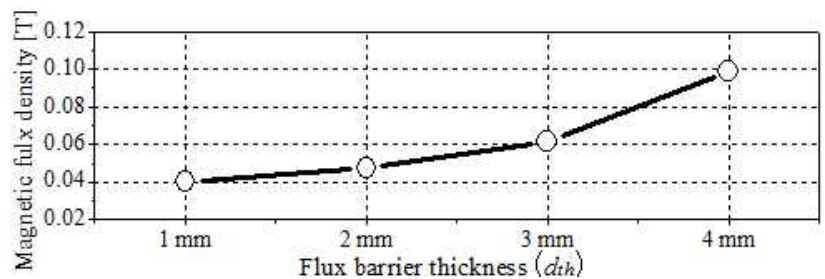

(b) The magnetic flux density on the shaft

Fig. 6. The optimization results for flux barrier thickness.

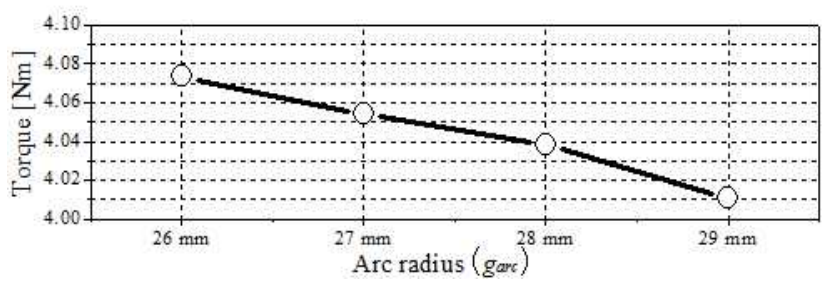

(a) The average torque.

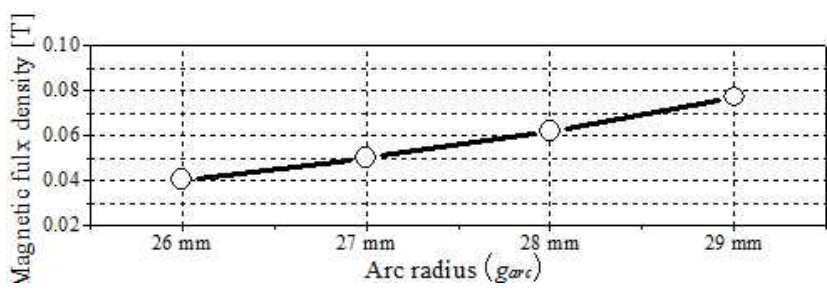

(b) The magnetic flux density on the shaft.

Fig. 7. The optimization results for arc size.

Table 1. Final optimized results

\begin{tabular}{c|c}
\hline Quantity & Value \\
\hline Distance between the magnet and the shaft & $5.3 \mathrm{~mm}$ \\
\hline Flux barrier thickness & $1 \mathrm{~mm}$ \\
\hline Arc radius & $26 \mathrm{~mm}$ \\
\hline
\end{tabular}




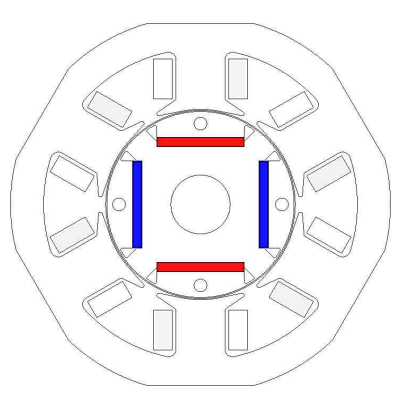

(a) Initial motor
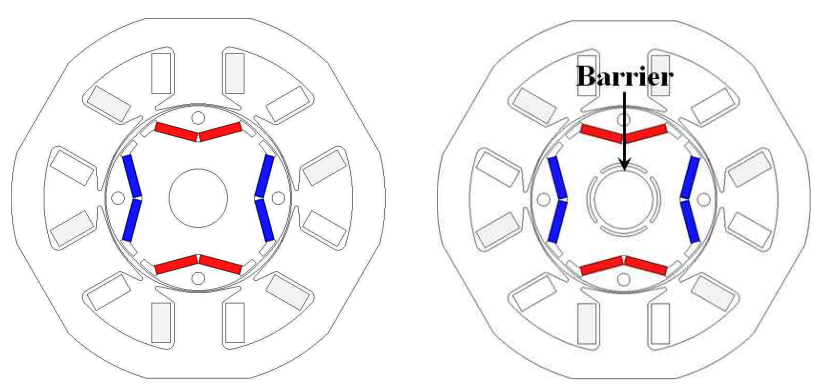

(b) V-shaped motor

(c) V-shaped with barrier motor

Fig. 8. The initial motor and the proposed motors

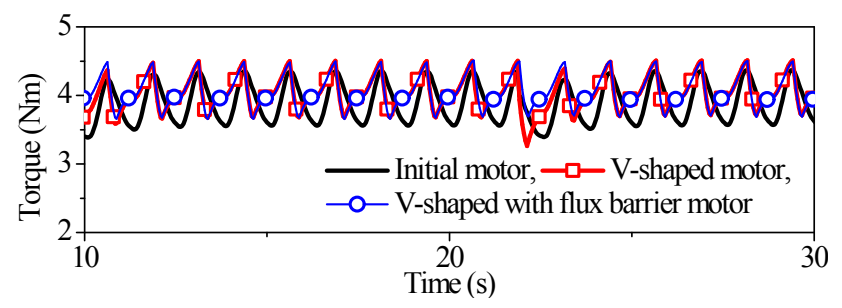

Fig. 9. Torque characteristics for each motor type

We did not change the size of the magnet [8-11].

Fig. 8 shows the initial motor and the proposed motors. In the case of the proposed motors, shaft voltage is suppressed by increasing the $C_{m g}$ value and reducing the $C_{r}$ value. When $C_{m g}$, increases, the distance between the magnet and the shaft $\left(d_{m}\right)$ decreases. When the $\mathrm{Cr}$ decreases, the air-gap length of the arc part $\left(g_{l}\right)$ is increases. So, shaft voltage is suppressed by decreasing the linkage magnetic flux on the shaft.

Fig. 9 shows the torque characteristics for each motor type. The average torques for each motor is almost same because we focused on motor design which can maintain output characteristics when we applied V-shape magnet and flux barriers. Fig. 10 shows the manufactured models.

$$
\begin{gathered}
C_{r}=f\left(g_{a r c}\right) \quad C_{m g}=f\left(\theta_{P M}, d_{m}, d_{t h}\right) \\
V_{s h}=f\left(C_{r}, C_{m g}\right)
\end{gathered}
$$

\section{Analysis and Results}

Figs. 10(a), (b), and (c) show the experimental results

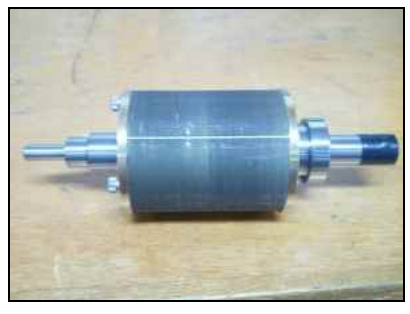

(a) V-shaped rotor

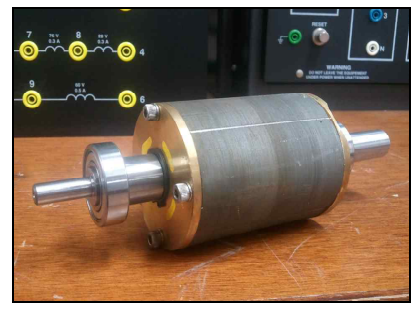

(b) Flux barrier rotor
Fig. 10. The proposed rotors

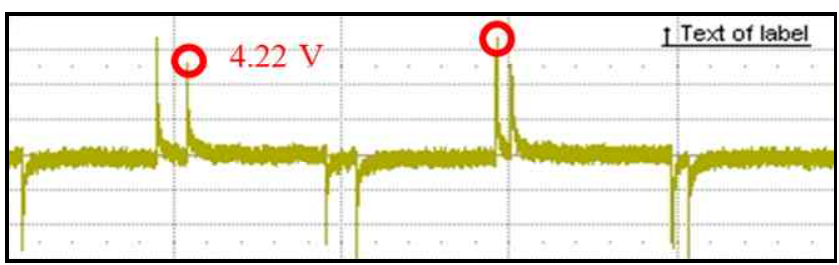

(a) The shaft voltage of initial motor.

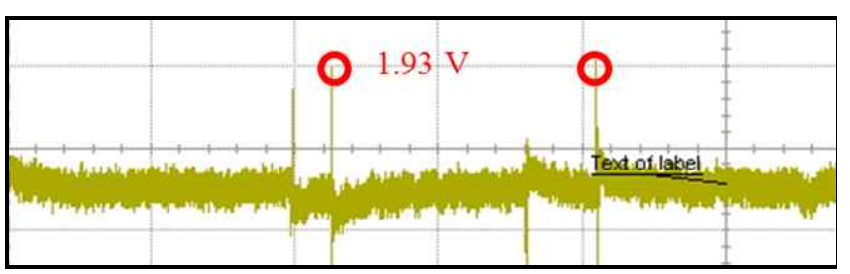

(b) The shaft voltage of only V-shape motor.

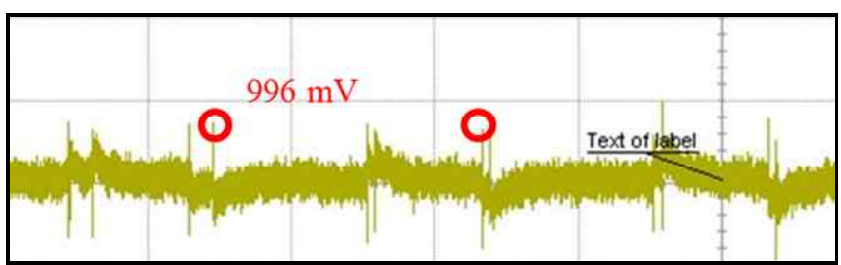

(c) The shaft voltage of V-shape with flux barrier motor.

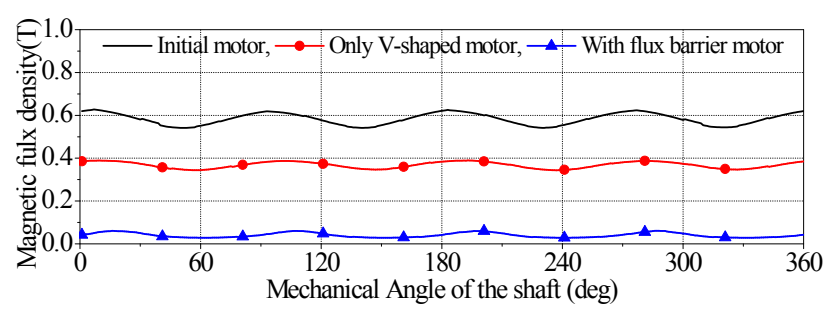

(d) The magnetic flux density on the shaft.

Fig. 11. The experimental result of shaft voltage and the magnetic flux

for the shaft voltage of the initial and the proposed motors. Fig. 10(d) shows the simulation results for the total magnetic flux density of the shaft. The shaft voltage of the proposed motors is lower than the shaft voltage of initial model.

The permissible range of the shaft voltage of the ball bearing is $2 \mathrm{~V}$. Therefore, the $\mathrm{V}$-shaped and flux barrier 


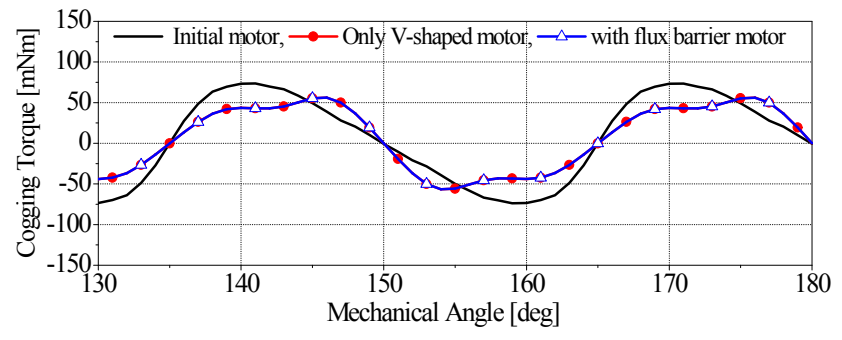

(a) The cogging torque

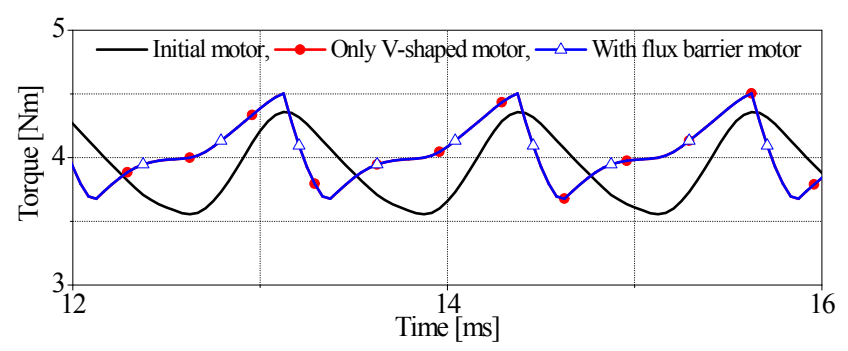

(b) The commutation torque.

Fig. 12. The commutation torque and the cogging torque

motors can be prevented bearing fault. Fig. 11(a) shows the cogging torques. The shaft voltages of the proposed models are lower than for the initial motor. The reduced cogging torque can be checked by an applied arc in the rotor. Fig. 11(b) shows the commutation torques. The ripple of the commutation torque is reduced by the arc-shaped rotor and V-shaped magnet. The simulation results for the shaft voltage are without the bearing.

\section{Conclusion}

In this study, in order to detail analysis of the shaft voltage, we divided the shaft voltage into two types of shaft voltages such as inherent and extrinsic shaft voltage. First, inherent shaft voltage depends on rotor configuration because it is induced by linkage flux between main magnetic flux and shaft. Thus, it should be considered when design the motor. In addition, it was calculated by Faraday's law. On the other hand, extrinsic shaft voltage is induced by several external factors such as electrostatic, unbalanced magnetic field, external power supply and electromagnetic factors. All of occurrences of shaft voltage could lead to bearing fault, and then the industrial production will be stopped.

Therefore, we proposed method for suppressing shaft voltage through an improved PM shape from the parallelshape PM to V-shape PM and inserting barriers surrounding shaft.

\section{Acknowledgements}

This research was supproted by the MSIP(Ministry of
Science, ICT\&Future Planning), Korea, under the CITRC (Convergence Information Technology Research Center) support program (NIPA-2014-H0401-14-1001) supervised by the NIPA(National IT Industry Promotion Agency) and the Energy Efficiency \& Resources of the Korea Institute of Energy Technology Evaluation and Planning(KETEP) grant funded by the Korea government Ministry of Knowledge Economy (No. 20122010100130 )

\section{References}

[1] I. S. Jung, H. G. Sung, Y. D. Chun, and J. H. Borm, "Magnetization modeling of a bonded magnet for performance calculation of inner-rotor type BLDC motor," IEEE Trans. on Mag., vol. 37, no. 4, pp. 2810-2813, July 2001.

[2] H. William Oh and A. Willwerth, "Shaft grounding a solution to motor bearing currents," Refrigerating and Air-Conditioning Engineers, Inc. Published in ASHRAE Trans., vol. 114, no. 2, 2008.

[3] T. Maetani, S. Morimoto, K. Iimori, Y. Isomura, and A. Watanabe, "Approaches to suppressing shaft voltage in brushless DC motor driven by PWM inverter," presented at 2011 Int. Conf. Elect. Mach. Syst. (ICEMS), pp. 1-6.

[4] J. Adabi, F. Zare, G. Ledwich, A. Ghosh, and R. D. Lorenz, "Bearing damage analysis by calculation of capacitive coupling between inner and outer races of a ball bearing," presented at the Conf. Power Electron. and Motion Control, pp. 903-907, Sept. 2008.

[5] J. Adabi, F. Zare, A. Ghosh, and R. D. Lorenz, "Calculations of capacitive couplings in induction generators to analyse shaft voltage," IET Power Electron., vol. 3, no. 3, pp. 379-390, 2010.

[6] A. Muetze and A. Binder, "Calculation of influence of insulated bearings and insulated inner bearing seats on circulating bearing currents in machines of inverter-based drive systems," IEEE Trans. Ind. Appl., vol. 42, no. 4, pp. 965-972, 2006.

[7] A. Muetze, and A. Binder, "Techniques for measurement of parameters related to inverter-induced bearing currents," IEEE Trans. Ind. Appl., vol. 43, no. 5, pp. 1068-1074, 2007.

[8] G. H. Kang, Y. D. Son, G. T. Kim, and J. Hur, "The novel cogging torque reduction method for interior type permanent magnet motor," IEEE Trans. Ind. Appl., vol. 45, pp. 161-167, Jan. 2009.

[9] A. Kioumarsi, M. Moallem, and B. Fahimi, "Mitigation of Torque Ripple in Interior Permanent Magnet Motors by Optimal Shape Design," IEEE Trans. Mag., vol. 42, no. 11, pp. 3706-3711, 2006.

[10] T. J. E Miller, Design of Brushless Permanent Magnet Motor, Clarendo press, Oxford, 1994.

[11] G. H. Kang, J. Hur, B. W. Kim and B. K. Lee, "The shape design of interior type permanent magnet BLDC 
motor for minimization of mechanical vibration," IEEE Conf. Energy Convers., pp. 2409 - 2414, Sep. 2009.

[12] Kyung-Tae Kim, Jin Hur, "Reduction of Shaft Voltage by the Flux-path Design in IPM-Type BLDC Motor" 2013 International Conference on Electrical Machines and Systems, pp. 803-806, Oct. 2013.

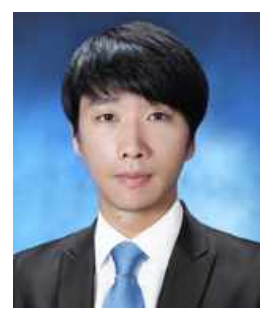

Kyung-Tae Kim was born in Busan, Korea. He received his B.S. and M.S. in Electrical Engineering from the University of Ulsan, Ulsan, Korea, in 2010 and 2012, respectively. Since 2012, he has been working towards his $\mathrm{Ph} . \mathrm{D}$. at the University of Ulsan. His current research interests include motor design and fault diagnosis of the motor.

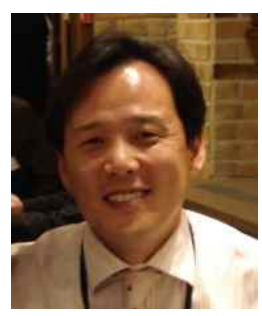

Jin Hur (S'93-M'98-SM'03) received his Ph.D. in Electrical Engineering from Hanyang University, Seoul, Korea, in 1999. From 1999 to 2000, he was with the Department of Electric Engineering, Texas A\&M University, College Station, TX, as a Postdoctoral Research Associate. From 2000 to 2001, he was a Research Professor of Electrical Engineering for BK21 projects at Hanyang University. From 2002 to 2007, he was a Director of Intelligent Mechatronics Research Center, Korea Electronics Technology Institute (KETI), Puchon, Korea, where he worked on the development of special electric machines and systems. Since 2008, he has been an Associate Professor, School of Electric Engineering, University of Ulsan, Ulsan, Korea. He is the author of over 140 publications on electric machine design, analysis and control, and power electronics. He has 1 granted pending US patent and 20 granted pending Korean patents. His current research interests include highperformance electrical machines, modeling, drives, new concept actuators for special purposes and numerical analysis of electromagnetic fields. Dr. Hur is working as an Associate Editor for IEEE Transaction on Power. 